\title{
Constraining Transient Climate Sensitivity Using Coupled Climate Model Simulations of Volcanic Eruptions
}

\author{
TIMOTHY M. MERLIS \\ McGill University, Montreal, Quebec, Canada \\ ISAAC M. HELD \\ NOAA/Geophysical Fluid Dynamics Laboratory, Princeton, New Jersey \\ GEORGIY L. STENCHIKOV \\ King Abdullah University of Science and Technology, Thuwal, Saudi Arabia \\ FANRONG ZENG AND LARRY W. HOROWITZ \\ NOAA/Geophysical Fluid Dynamics Laboratory, Princeton, New Jersey
}

(Manuscript received 18 March 2014, in final form 4 July 2014)

\begin{abstract}
Coupled climate model simulations of volcanic eruptions and abrupt changes in $\mathrm{CO}_{2}$ concentration are compared in multiple realizations of the Geophysical Fluid Dynamics Laboratory Climate Model, version 2.1 (GFDL CM2.1). The change in global-mean surface temperature (GMST) is analyzed to determine whether a fast component of the climate sensitivity of relevance to the transient climate response (TCR; defined with the $1 \% \mathrm{yr}^{-1} \mathrm{CO}_{2}$-increase scenario) can be estimated from shorter-time-scale climate changes. The fast component of the climate sensitivity estimated from the response of the climate model to volcanic forcing is similar to that of the simulations forced by abrupt $\mathrm{CO}_{2}$ changes but is $5 \%-15 \%$ smaller than the TCR. In addition, the partition between the top-of-atmosphere radiative restoring and ocean heat uptake is similar across radiative forcing agents. The possible asymmetry between warming and cooling climate perturbations, which may affect the utility of volcanic eruptions for estimating the TCR, is assessed by comparing simulations of abrupt $\mathrm{CO}_{2}$ doubling to abrupt $\mathrm{CO}_{2}$ halving. There is slightly less $(\sim 5 \%)$ GMST change in $0.5 \times \mathrm{CO}_{2}$ simulations than in $2 \times \mathrm{CO}_{2}$ simulations on the short $(\sim 10 \mathrm{yr})$ time scales relevant to the fast component of the volcanic signal. However, inferring the TCR from volcanic eruptions is more sensitive to uncertainties from internal climate variability and the estimation procedure.

The response of the GMST to volcanic eruptions is similar in GFDL CM2.1 and GFDL Climate Model, version 3 (CM3), even though the latter has a higher TCR associated with a multidecadal time scale in its response. This is consistent with the expectation that the fast component of the climate sensitivity inferred from volcanic eruptions is a lower bound for the TCR.
\end{abstract}

\section{Introduction}

Constraining the magnitude of the response of surface temperature to changes in the concentrations of greenhouse gases and other radiative forcing agents is a central goal of climate research. A substantial amount of

Corresponding author address: Timothy M. Merlis, McGill University, 805 Sherbrooke Street West, Montreal QC H3A 2K6, Canada.

E-mail: timothy.merlis@mcgill.ca research has addressed the magnitude of the equilibrium response of the global-mean surface temperature to doubled carbon dioxide concentration, the equilibrium climate sensitivity (ECS). However, the climate system, and the oceans in particular, will be out of equilibrium with the radiative forcing on the time scale ( $\$ 100 \mathrm{yr})$ of immediate interest. In addition, the relationship between the transient temperature change over a century or less and the equilibrium climate sensitivity varies between climate models because of different physics and feedbacks coming into play on longer time scales (e.g., 
Winton et al. 2010). It is, therefore, of interest to employ observed climate changes to directly constrain the magnitude of the response to transient forcing (e.g., Gregory and Forster 2008).

Here, we explore the utility of volcanic eruptions as a constraint on the transient climate response (TCR), defined as the magnitude of the global-mean surface temperature response at the time of doubled $\mathrm{CO}_{2}$ concentration when $\mathrm{CO}_{2}$ is increased at the rate of $1 \% \mathrm{yr}^{-1}$. The degree to which the climate response to volcanic eruptions constrains the equilibrium climate sensitivity has been examined in several studies (Lindzen 1994; Lindzen and Giannitsis 1998; Wigley et al. 2005; Yokohata et al. 2005; Boer et al. 2007; Bender et al. 2010). In addition, the observed response to the eruption of Mount Pinatubo has been used to test the performance of individual climate feedbacks in climate models (Soden et al. 2002). But making a connection between the volcanic temperature response on time scales of less than a decade to the equilibrium response requires knowledge of the ocean heat uptake. It also requires knowledge of the "efficacy" of heat uptake (Winton et al. 2010). The hope motivating this study is that one can use the volcanic temperature response to constrain TCR without any need to explicitly estimate heat uptake or its efficacy.

The relevance of TCR is not limited to the specific $1 \% \mathrm{yr}^{-1}$ scenario. The idealized setup used to define TCR is designed to probe the time scales of most relevance to the response to increasing greenhouse gases in the past 50-100 years. More generally, it has been argued that TCR can be a useful measure of the response to radiative forcing on time scales for which the near-surface ocean has largely equilibrated but the climate system is out of radiative equilibrium because of the storage of heat by the deep ocean, with the deep ocean acting as an infinite heat reservoir. We use the term "transient climate sensitivity" (TCS) more generally when the system can be thought of as residing in this regime-as indicated by fitting general circulation model (GCM) results with simple energy balance models (see section $2 b$ ).

More generally, a plausible form for the global-mean surface temperature response to a step function increase in $\mathrm{CO}_{2}$ at time $t=0$, consistent with the typical behavior simulated in GCMs, is a sum of exponentials representing the relaxation of different parts of the system to their new equilibrium

$$
\Delta T(t)=\mathcal{F} \sum_{i} \alpha_{i}\left[1-\exp \left(-t / \tau_{i}\right)\right]
$$

Here $\mathcal{F}$ is the forcing and the equilibrium response is $\mathcal{F} \sum_{i} \alpha_{i}$, with the time scales $\tau_{i}$ increasing with index $i$. Equivalently, the response to a forcing localized in time, such as a volcano, idealized as a $\delta$ function at time $t=0$, takes the form

$$
\Delta T(t)=\widetilde{\mathcal{F}} \sum_{i} \alpha_{i} \tau_{i}^{-1} \exp \left(-t / \tau_{i}\right)
$$

where $\widetilde{\mathcal{F}}=\int \mathcal{F}(t) d t$ is the integrated forcing. Note that this is an idealization of the true forcing of a volcanic eruption which typically decays with a time scale of about 1 yr. See van Hateren (2013) for an example of using a discrete spectrum to represent the time-dependent response of global-mean surface temperature to radiative forcing. There are parts of the climate system, such as the ocean mixed layer, that may be well approximated by a single discrete time scale; however, this is not the case in general, and one should think of the discrete sum as an approximation to a continuous spectrum of time scales. One common model uses a fixed time scale to represent the adjustment of the ocean mixed layer and all faster processes, and a continuous, diffusive component as an approximation to slower deep ocean adjustments (e.g., Siegenthaler and Oeschger 1984). For some purposes, two time scales, one for the fast surface ocean and one for the slower deep ocean adjustment, are adequate (Held et al. 2010; Geoffroy et al. 2013; Kostov et al. 2014).

To address the connection between volcanic responses and TCR, it is useful, first of all, to quantitatively evaluate whether the amplitude of the fast ( $\$ 10 \mathrm{yr}$ ) component of the response of global-mean surface temperature to an abrupt increase in $\mathrm{CO}_{2}$ can be constrained by the response of global-mean surface temperature to volcanic eruptions. This connection to TCR is more likely to be a tight one if this fast component of the climate response is a larger fraction of the response realized on the century time scale. In the ensemble of coupled GCMs from phase 5 of the Coupled Model Intercomparison Project (CMIP5), the fast component of the climate response typically accounts for somewhat more than half of the equilibrium response and more than three-quarters of the century-scale response in models forced with abruptly increased $\mathrm{CO}_{2}$ (Geoffroy et al. 2013). This result is encouraging for constraining TCR and the response to $\mathrm{CO}_{2}$ forcing from preindustrial to present with the volcanic response. But it also suggests that the transient sensitivity inferred from the response to volcanic forcing could be a significant underestimate of the TCR. The increase in response as the time scale increases [(1)] is familiar when comparing ECS and TCR but is also potentially relevant when trying to infer TCR from volcanic responses.

Another potential issue is the linearity underlying this picture, and the symmetry between warming and cooling perturbations that linearity implies. Asymmetry between warming and cooling is known to occur in models of 
long-time-scale transient climate changes (Stouffer 2004), and one can speculate that it also relevant for comparing transient volcanic responses and TCR.

We address these questions by examining the response of a comprehensive coupled climate model [Geophysical Fluid Dynamics Laboratory Climate Model, version 2.1 (GFDL CM2.1), section 2a] to $1 \% \mathrm{yr}^{-1}$ increase in $\mathrm{CO}_{2}$ concentration, to abrupt increases and decreases of $\mathrm{CO}_{2}$ concentration, and to an estimate of the stratospheric aerosol forcing caused by the eruption of Mount Pinatubo. The results of these GCM simulations are interpreted using a simple two-box energy balance model of the global climate (section 2b). The GFDL Climate Model, version 3 (CM3), has about a 30\% larger TCR than CM2.1, but much of this increase emerges on time scales intermediate between 10 and 100 years: the response of the two GCMs is similar in the first 10 years after an abrupt increase in $\mathrm{CO}_{2}$ (Winton et al. 2013). To the extent that these intermediate, multidecadal time scales are not excited appreciably by a single volcanic eruption, the expectation would be that volcanic responses in CM2.1 and CM3 would be more similar to each other than the values of TCR in these two models. We therefore compare the volcanic response of GFDL CM2.1 to CM3 with this perspective in mind. However, we emphasize CM2.1 in our results as its century-scale response to $\mathrm{CO}_{2}$-with a large fraction of the warming contained in the fast component of the response-is more typical of CMIP5 models (Geoffroy et al. 2013).

We do not attempt to use observations of the response to volcanoes to obtain quantitative constraints of Earth's TCR here; we focus instead on theoretical issues that need to be understood to determine the limitations of this approach, even with perfect data on the temperature response and the radiative forcing. In particular, we do not address the uncertainty in estimating the radiative forcing resulting from a volcanic eruption such as Mount Pinatubo.

\section{Models and analysis method}

\section{a. GCM description}

\section{1) $\mathrm{CM} 2.1$}

The Geophysical Fluid Dynamics Laboratory CM2.1 is a coupled ocean-atmosphere GCM that participated in phase 3 of CMIP (CMIP3), which occurred in support of the Intergovernmental Panel on Climate Change Fourth Assessment Report. A description of the CM2.1 formulation and control climate can be found in Delworth et al. (2006). CM2.1 has an ECS of $3.4 \mathrm{~K}$ and a TCR of $1.5 \mathrm{~K}$ (Stouffer et al. 2006). Held et al. (2010) showed the model response to an abrupt $\mathrm{CO}_{2}$ doubling features a plateau in global-mean surface temperature of approximately $1.5 \mathrm{~K}$ that persisted for half a century, after a rapid $\sim 10$-yr warming.

Here, we compare a 10 -member ensemble of $20-\mathrm{yr}$ simulations forced by abrupt $\mathrm{CO}_{2}$ doubling and halving to an ensemble forced by stratospheric aerosol forcing designed to represent the 1991 eruption of Mount Pinatubo. The 10 positive and 10 negative $\mathrm{CO}_{2}$ perturbation simulations branch off from a 400-yr segment of a preindustrial control simulation. The initial conditions for different ensemble members are spaced 40 years apart in the control integration. Each perturbation simulation is compared to the segment of the control covering the same time interval.

The Pinatubo simulations that we analyze are identical to those described in Stenchikov et al. (2009). Starting with a 300-yr control with fixed 1990 forcing, 10 Pinatuboforced perturbation simulations are initialized from times of positive phase of El Niño-Southern Oscillation (ENSO) in a 300-yr 1990 control simulation ${ }^{1}$ - consistent with the presence of positive ENSO phase when the actual eruption occurred. We performed 10 additional perturbation simulations by sampling initial conditions in the negative, La Niña, phase of ENSO. As in the $\mathrm{CO}_{2}$-forced simulations, responses are computed by subtracting the corresponding segment of the control simulation, except for in section 5 .

The radiative forcing $\mathcal{F}$ is computed from the fixed sea surface temperature (SST), fixed sea ice version of the GFDL GCM [Atmospheric Model, version 2.1 (AM2.1); Anderson et al. 2004] using observed SSTs and sea ice extents. In these simulations, stratospheric and land temperatures are free to adjust, and ultrafast tropospheric adjustments can occur (e.g., cloud changes that result directly from the perturbed radiative forcing that occur before the SST responds). The $\mathrm{CO}_{2}$ radiative forcing is determined from a 5-member ensemble of 20 -yr integrations. The Pinatubo radiative forcing is determined from a 10-member ensemble of 15-yr integrations that have the same time-varying prescribed stratospheric aerosols as the coupled simulations. The top-of-atmosphere $2 \times \mathrm{CO}_{2}$ radiative forcing is

\footnotetext{
${ }^{1}$ The effect of the difference in mean climate between the control simulations (preindustrial for $\mathrm{CO}_{2}$ perturbations versus 1990 for volcanic perturbations) appears to be negligible for the radiative perturbations of interest here: CM2.1's TCR is $1.6 \mathrm{~K}$ when the $1 \% \mathrm{yr}^{-1} \mathrm{CO}_{2}$ increase begins from a 1990 control simulation and is $1.5 \mathrm{~K}$ when the $\mathrm{CO}_{2}$ increase begins from a preindustrial control simulation. Determining whether this slight difference is a genuine dependence of the TCR on the mean climate state or is the result of sampling internal variability would require additional realizations (Liang et al. 2013).
} 
$\mathcal{F}_{2 \times \mathrm{CO}_{2}}=3.52 \mathrm{~W} \mathrm{~m}^{-2}$ [which is larger by 0.04 than the number cited in Held et al. (2010) because of differences in sampling]. The $0.5 \times \mathrm{CO}_{2}$ radiative forcing is $\mathcal{F}_{0.5 \times \mathrm{CO}_{2}}=$ $-3.57 \mathrm{~W} \mathrm{~m}^{-2}$. The deviation from perfectly logarithmic dependence on $\mathrm{CO}_{2}$ concentration is not significant as the standard deviation across the ensemble members is about $0.10 \mathrm{~W} \mathrm{~m}^{-2}$. The time-integrated volcanic forcing in these simulations is $\int \mathcal{F}_{\text {Pina }} d t=-6.5 \mathrm{~W} \mathrm{~m}^{-2}$ yr.

The land surface temperature evolves in these fixedSST radiative forcing simulations. For $2 \times \mathrm{CO}_{2}$ and $0.5 \times$ $\mathrm{CO}_{2}$ simulations, the global-mean (indicated by $\langle\cdot\rangle$ ) surface temperature change is $\Delta\left\langle T_{s}\right\rangle=0.17$ and $-0.18 \mathrm{~K}$, respectively. The time-integrated global-mean surface temperature change in the Pinatubo radiative forcing simulations is $\int \Delta\left\langle T_{s}\right\rangle d t=-0.25 \mathrm{~K}$ yr. (The temperature changes averaged over land only are a factor of 3 larger). Accounting for the effect of these land surface temperature changes on the top-of-atmosphere radiation anomalies would change the radiative forcing estimates by approximately $10 \%$; we do not make such adjustments. Comparing the volcanic and $\mathrm{CO}_{2}$ responses, these land temperature changes are roughly proportional to the forcing, so adjusting the forcing to approximately account for the land responses would have little effect on the relative sensitivity to these two forcing agents.

\section{2) $\mathrm{CM} 3$}

The Geophysical Fluid Dynamics Laboratory CM3 is a coupled ocean-atmosphere GCM that participated in CMIP5, which occurred in support of the Intergovernmental Panel on Climate Change Fifth Assessment Report. A description of the CM3 formulation and control climate can be found in Griffies et al. (2011). The atmospheric component of CM3 (AM3) is substantially different from AM2.1 and is described in Donner et al. (2011). CM3 has an ECS of $4.6 \mathrm{~K}$ and a TCR of $1.9 \mathrm{~K}$ (Winton et al. 2013).

The CM3 Pinatubo simulations that we analyze use the same prescribed stratospheric aerosols as in CM2.1. The 12 Pinatubo perturbation simulations branch off from a 330-yr preindustrial control simulation. The perturbation simulations are integrated for 15 years, starting from initial conditions spaced 20 years apart in the control integration. Therefore, the phase of ENSO is more uniformly sampled in the $\mathrm{CM} 3$ simulations than in the CM2.1 simulations, where the initial conditions were designed to sample the extreme phases of ENSO. Each perturbation simulation is compared to the segment of the control covering the same time interval. A threemember ensemble of AM3 with fixed SSTs, fixed sea ice, and time-varying volcanic forcing suggests that the global-mean radiative forcing $\mathcal{F}_{\text {Pina }}$ is the same, within sampling variability, as that of AM2.1.

\section{b. Two-box energy balance model}

Following Held et al. (2010) and Gregory (2000), we interpret climate changes using a two-box model of the global climate, with one box representing the nearsurface ocean and the other representing the deep ocean. We are interested in the limitations of this model as well as its ability to fit the GCM results of interest. A physical picture of this type is needed to go beyond the fit to the temperature evolution and interpret it in terms of radiative restoring and ocean heat uptake. The model temperatures are deviations from an equilibrium climate, and the governing equations are

$$
c_{F} \partial_{t} T=-\beta T-\mathcal{H}+\mathcal{F} \quad \text { and } \quad c_{D} \partial_{t} T_{D}=\mathcal{H},
$$

with surface temperature $T$ (with heat capacity $c_{F}$ ), topof-atmosphere radiative forcing $\mathcal{F}$, heat exchange with the deep ocean $\mathcal{H}$, top-of-atmosphere radiative restoring $\beta T$, and deep ocean temperature $T_{D}$ (with heat capacity $c_{D}$ ). The parameter $\beta$ is the linearization of the top-ofatmosphere radiation with respect to the global-mean surface temperature (i.e., it is the sum of the radiative feedbacks, which include the surface albedo, water vapor, lapse rate, and cloud feedbacks). Note that we suppress the global-mean $\langle\cdot\rangle$ and change $\Delta$ notation in discussing the box model. Explicit solutions to (3) for idealized forcing scenarios are presented in Geoffroy et al. (2013).

If the heat exchange between the boxes is proportional to the temperature difference $\mathcal{H}=\gamma\left(T-T_{D}\right)$, the model reduces to

$$
c_{F} \partial_{t} T=-\beta T-\gamma T+\mathcal{F} \equiv-\widetilde{\beta} T+\mathcal{F}
$$

for times before the deep ocean has changed substantially $\left(T_{D} \approx 0\right)$. A TCS can be defined as $\mathcal{F} / \widetilde{\beta}$ with $\widetilde{\beta}=\beta+\gamma$. The TCS is a good approximation to the temperature change that occurs after the near-surface ocean has largely equilibrated $\left(\partial_{t} T \approx 0\right)$, but before the deep ocean has adjusted substantially $\left(T_{D} \approx 0\right)$. The form of the TCS $(\mathcal{F} / \widetilde{\beta})$ is similar to that of the ECS $(\mathcal{F} / \beta)$, which is realized when the ocean has come into equilibrium $\left(\partial_{t} T_{D}=0\right)$. Thus, the ocean heat uptake acts as a negative transient climate feedback on the globalmean surface temperature change (cf. Raper et al. 2002; Winton et al. 2010). The fast time scale of the two-box model can be defined as $\tau_{F}=c_{F} / \widetilde{\beta}$. Gregory and Forster (2008) refer to $\widetilde{\beta}$ as the "climate resistance."

Here, we emulate results of coupled GCM simulations using this framework by estimating $\widetilde{\beta}$ in (4). The slow time scale of the two-box model $\left[\tau_{s}=c_{D} \widetilde{\beta}(\beta \gamma)^{-1}\right]$ is presumed to be sufficiently large that explicitly including it is inconsequential on the time scale of an isolated 
volcanic eruption and the observable temperature response to that eruption. Held et al. (2010) showed that the two-box model with TCS $\approx 1.5 \mathrm{~K}$ and $\tau_{F} \approx 4 \mathrm{yr}$ well approximates CM2.1's global-mean surface temperature response to abrupt $\mathrm{CO}_{2}$ doubling and to the timedependent twentieth-century radiative forcing, including volcanic eruptions (see also Padilla et al. 2011). A central goal of this work is to assess the extent to which $\widetilde{\beta}$ estimated from volcanic eruptions is consistent with $\widetilde{\beta}$ of $\mathrm{CO}_{2}$ perturbations. ${ }^{2}$

For impulsive radiative forcing such as that due to a volcanic eruption at time $t=0$, the time-integrated temperature response of (4) is approximated by the ratio of the integrated radiative forcing and $\widetilde{\beta}$

$$
\int_{0}^{\tau_{I}} T d t \approx \frac{\int_{0}^{\tau_{I}} \mathcal{F} d t}{\beta+\gamma},
$$

for integration times $\tau_{I}$ long enough that the heat storage is negligible in the near-surface energy balance but short enough that the deep ocean temperature change can be neglected. The value of this approach depends on there being a large enough gap between the fast and slow adjustment time scales that this integral does not depend significantly on the choice of the integration time $\tau_{I}$.

As the system equilibrates fully, the (negative) heat anomaly in the deep ocean (Church et al. 2005; Stenchikov et al. 2009) must eventually decay through reduction of the energy loss to space, requiring there to be a long-lasting small surface temperature response (e.g., Wigley et al. 2005). In the context of the two-box model with well-separated time scales, the integrated magnitude of this temperature response during the slow adjustment differs from the magnitude of the fast temperature response by the $\operatorname{ratio}^{3} \gamma / \beta$ :

$$
\int_{\tau_{I}}^{\infty} T d t \approx \frac{\gamma}{\beta} \int_{0}^{\tau_{I}} T d t
$$

While the integrated slow response is nonnegligible, the magnitude of the temperature perturbation during the slow adjustment phase is smaller than that in the fast response by the additional factor of the ratio of fast to

\footnotetext{
${ }^{2}$ Good et al. (2011), Olivié et al. (2012), and Geoffroy et al (2013) have investigated related issues concerning the similarity between different $\mathrm{CO}_{2}$-forcing scenarios in GCMs. These studies found parameters estimated in one $\mathrm{CO}_{2}$-forcing scenario generally capture the GCM behavior in other $\mathrm{CO}_{2}$-forcing scenarios.

${ }^{3}$ This results from a dominant balance on long time scales between the radiative restoring and exchange with the deep box of the accumulated energy storage over the period of radiative forcing.
}

slow time scales-see (2). We assume that this slow temperature response is too small to be observable for a single volcanic eruption of the magnitude of Pinatubo.

The limitations of this two-time-scale perspective can impact our results in two ways. If the fast response itself consists of multiple time scales, this can introduce a sensitivity to the specifics of the fitting procedure used to estimate $\widetilde{\beta}$. If there are significant time scales in the response between that of the fast volcanic response and the multicentennial time scale of ocean equilibration (e.g., multidecadal time scales), they may emerge over the course of the $1 \% \mathrm{yr}^{-1} \mathrm{CO}_{2}$ increase scenario or in simulations of the response to twentieth-century forcing. This potentially weakens the connection between the estimate of TCS from the volcanic response and the changes occurring in these century-scale scenarios. We discuss both of these issues in what follows.

\section{c. Parameter estimation}

Various estimation procedures have been used to fit GCM responses with energy balance models (Boer et al. 2007; Padilla et al. 2011; Geoffroy et al. 2013). We choose to simply numerically integrate (4) over a range of parameters to determine the values that minimize the squared error with respect to the GCM-simulated globalmean surface temperature.

For the abrupt $\mathrm{CO}_{2}$ simulations, we simultaneously estimate $\widetilde{\beta}$ and $\tau_{F}$ by minimizing the squared error over the 20 simulated years. We refer to this as the "twoparameter fit." For volcanic radiative forcing, we use the relationship between the integrated radiative forcing and integrated temperature response (5) to estimate the TCS. The combined radiative feedback and ocean heat uptake efficiency $\widetilde{\beta}$ can be estimated without considering the fast time scale $\tau_{F}$ because

$$
\widetilde{\beta}=\frac{\int_{0}^{\tau_{I}} \mathcal{F} d t}{\int_{0}^{\tau_{I}} T d t} .
$$

The upper bound of time integration $\tau_{I}$ is chosen to be 15 years from the start of the volcanic eruption, which is sufficiently long that GCM-simulated temperature response is near zero (Fig. 1c). We refer to this as an "integral fit."

We have also performed two-parameter fits for the Pinatubo simulations, as in the $\mathrm{CO}_{2}$ simulations. This alternative procedure produces larger estimates of $\widetilde{\beta}-\mathrm{a}$ lower TCS. The estimates differ by $10 \%-20 \%$. This discrepancy results from the two-parameter fit weighing the initial (within $\sim 5 \mathrm{yr}$ of the eruption) temperature 

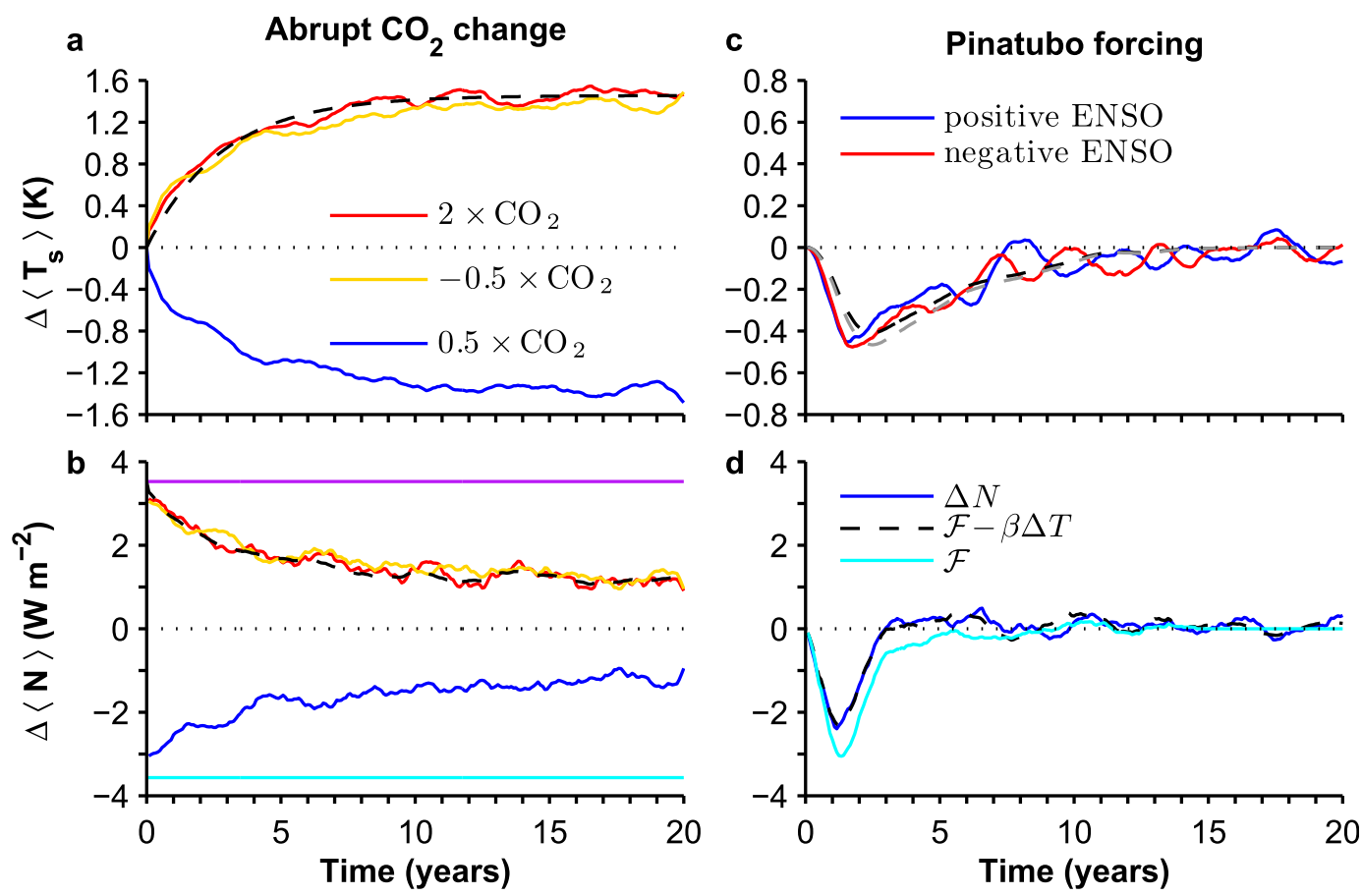

FIG. 1. (a) Change in global-mean surface temperature for abrupt $\mathrm{CO}_{2}$ simulations $\left(2 \times \mathrm{CO}_{2}\right.$, red line; $0.5 \times \mathrm{CO}_{2}$, blue line; and reflection of $0.5 \times \mathrm{CO}_{2}$ about zero, yellow line) with black dashed line showing the estimated parameters (Table 1) of the two-box model [(4)]. (b) Change in global-mean TOA net radiation [colors as in (a)], radiative forcing indicated by straight lines, and net radiation implied by the best estimate of $\beta$ (black dashed line). (c) Change in global-mean surface temperature for Pinatubo simulations with dashed lines showing the integral fit TCS estimate plotted with the $\mathrm{CO}_{2}$ time scale (positive ENSO, black, and negative ENSO, gray). (d) Change in global-mean TOA net radiation for positive ENSO phase simulations (blue), radiative forcing (light blue), and net radiation implied by the best estimate of $\beta$ (black dashed line). Negative ENSO phase simulations are similar (not shown). All quantities shown are 12-month running time averages of the ensemble mean of CM2.1 simulations.

change more strongly than later times, in contrast to the integral fitting technique that weighs all times equally. If we assume, for example, that there are two fast time scales, 6 months and 3 years, with $25 \%$ of the temperature response occurring on the smaller time scale, fitting with only one time scale underestimates the TCS, or the response on time scales longer than 10 years, by $16 \%$ when using the two-parameter fit. In contrast, the integral fit provides the desired answer. On this basis, if one is trying to optimize the relevance of the estimated TCS for the response to longer time scales, the integral fit is a better estimate. But the latter may also underestimate the response if the integrated temperature response has some sensitivity to the integration time $\tau_{I}$.

While we are primarily interested in estimating $\widetilde{\beta}$ without the need to decompose it into its two components, the partition of the TCS into the contributions from the sum of the climate feedbacks $\beta$ and the ocean heat uptake $\gamma$ is still of interest. We use the standard topof-atmosphere (TOA) radiation balance to separately estimate $\beta$ :

$$
N=-\beta T+\mathcal{F},
$$

with global-mean TOA net radiation $N$. This allows for a decomposition of the TCS into the TOA radiative flux component $\beta$ and the ocean heat uptake per unit temperature change $\gamma$. The inferred $\beta$ from examining the short-time-scale response will differ from that of the equilibrium climate sensitivity because the spatial pattern of the climate response evolves as equilibrium is approached (Winton et al. 2010; Armour et al. 2013). The global perspective of the box model can be preserved if an ocean heat uptake efficacy is introduced that modifies the relationship between the ocean heat uptake and the global-mean surface temperature (Winton et al. 2010). Physically, the efficacy factor represents the greater sensitivity of the global-mean surface temperature to high-latitude ocean heat uptake than to lowlatitude ocean heat uptake (in analogy to the nonunitary efficacies of non- $\mathrm{CO}_{2}$ radiative forcing agents; Hansen et al. 2005). As we are concerned here solely with the short time scales and not the approach to final equilibrium, the hope is that we can neglect possible sources of 
time-varying climate sensitivity on time scales of less than a century.

The volcanic aerosol radiative forcing may have a different efficacy than $\mathrm{CO}_{2}$. Hansen et al. (2005) and Yoshimori and Broccoli (2008) found solar constant and volcanic aerosol radiative forcing have efficacies of about 0.9 (i.e., $10 \%$ less global-mean surface temperature change per unit of radiative forcing compared to $\mathrm{CO}_{2}$ or $\beta_{\mathrm{VOLC}} \approx 1.1 \beta_{\mathrm{CO}_{2}}$ ) in long-term climate change simulations. This suggests that TCS estimates from the response of global-mean surface temperature response to volcanic forcing may underestimate the $\mathrm{CO}_{2}$ response. However, the equilibrium efficacy of volcanic forcing may be less relevant in the context of the transient responses we analyze.

\section{Abrupt $\mathrm{CO}_{2}$ change radiative forcing}

\section{a. GCM response: $C M 2.1$}

The ensemble- and global-mean surface temperature response to abrupt changes in $\mathrm{CO}_{2}$ concentration is shown in Fig. 1a. The temperature change reaches about $1.5 \mathrm{~K}$ by the end of the $20-\mathrm{yr}$ simulations. The $0.5 \times \mathrm{CO}_{2}$ simulations has a cooling of similar magnitude to the warming in the $2 \times \mathrm{CO}_{2}$ simulations; this is illustrated by the magenta line in Fig. 1a, which is the reflection of the $0.5 \times \mathrm{CO}_{2}$ temperature change about zero. The cooling in the $0.5 \times \mathrm{CO}_{2}$ simulation is somewhat smaller $(\sim 5 \%)$ than the warming in the $2 \times \mathrm{CO}_{2}$ simulation. The geographic pattern of the warming and cooling is largely similar between the $2 \times \mathrm{CO}_{2}$ and $0.5 \times \mathrm{CO}_{2}$ simulations (Fig. 2). The small difference between the global-mean surface temperature change in the $2 \times \mathrm{CO}_{2}$ and $0.5 \times \mathrm{CO}_{2}$ simulations is statistically significant at the $10 \%$ level using a two-sided Student's $t$ test for the 10 realizations averaged over the last 10 years.

The radiative forcing and change in TOA net radiation in the abrupt $\mathrm{CO}_{2}$ simulations are shown in Fig. 1b. The radiative imbalance at the TOA decreases over the 20 years of the simulations but is approximately $1 \mathrm{~W} \mathrm{~m}^{-2}$ out of equilibrium at the end of the integration. The magnitude of the net radiation anomalies is larger in the $0.5 \times \mathrm{CO}_{2}$ simulations than in the $2 \times \mathrm{CO}_{2}$ simulations by about $5 \%$. This is consistent with the expectation that there is more transient change in ocean heat content for cooling climate perturbations than for warming climate perturbations, which may arise because cooling perturbations destabilize, while warming perturbations stabilize, the subpolar ocean's stratification (Stouffer 2004; Bouttes et al. 2013). However, the magnitude of this asymmetry on these short time scales is very small,

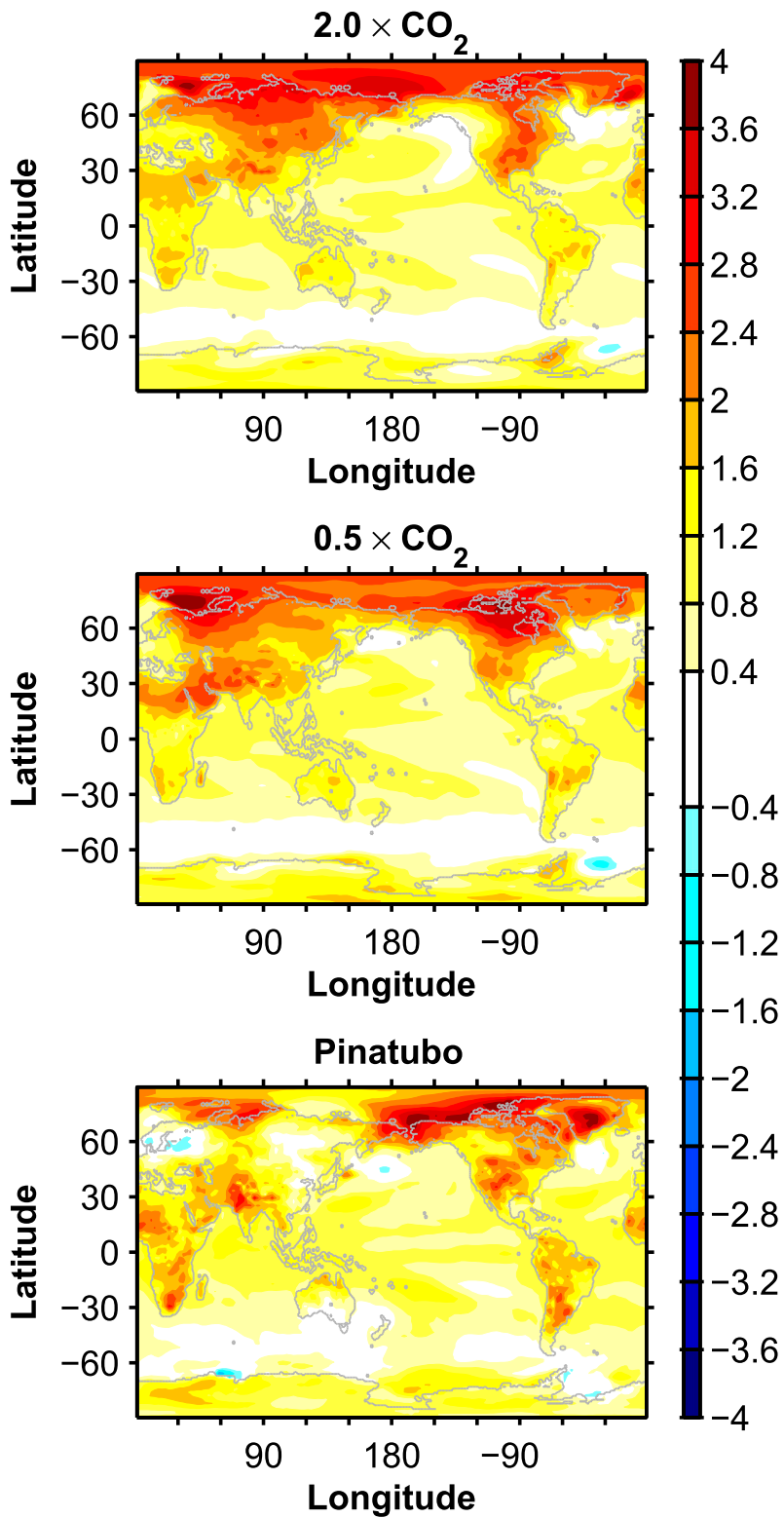

FIG. 2. Surface temperature change normalized by the globalmean surface temperature change $\Delta T_{s} /\left\langle\Delta T_{s}\right\rangle$ averaged over the first $5 \mathrm{yr}$ of the CM2.1 simulations for the ensemble of (top) $2 \times$ $\mathrm{CO}_{2}$ simulations, (middle) $0.5 \times \mathrm{CO}_{2}$ simulations, and (bottom) Pinatubo simulations, where the simulations initialized from the positive and negative phase of ENSO have been averaged together. The ratio is computed for individual years prior to averaging over $5 \mathrm{yr}$.

in this model, compared to other sources of uncertainty involved in using volcanic responses to constrain sensitivity.

The time-integrated temperature response, radiative forcing, and net TOA radiation response are shown in Fig. 3. The integrated response in these variables is close to linear in time for the abrupt $\mathrm{CO}_{2}$ simulations, as 

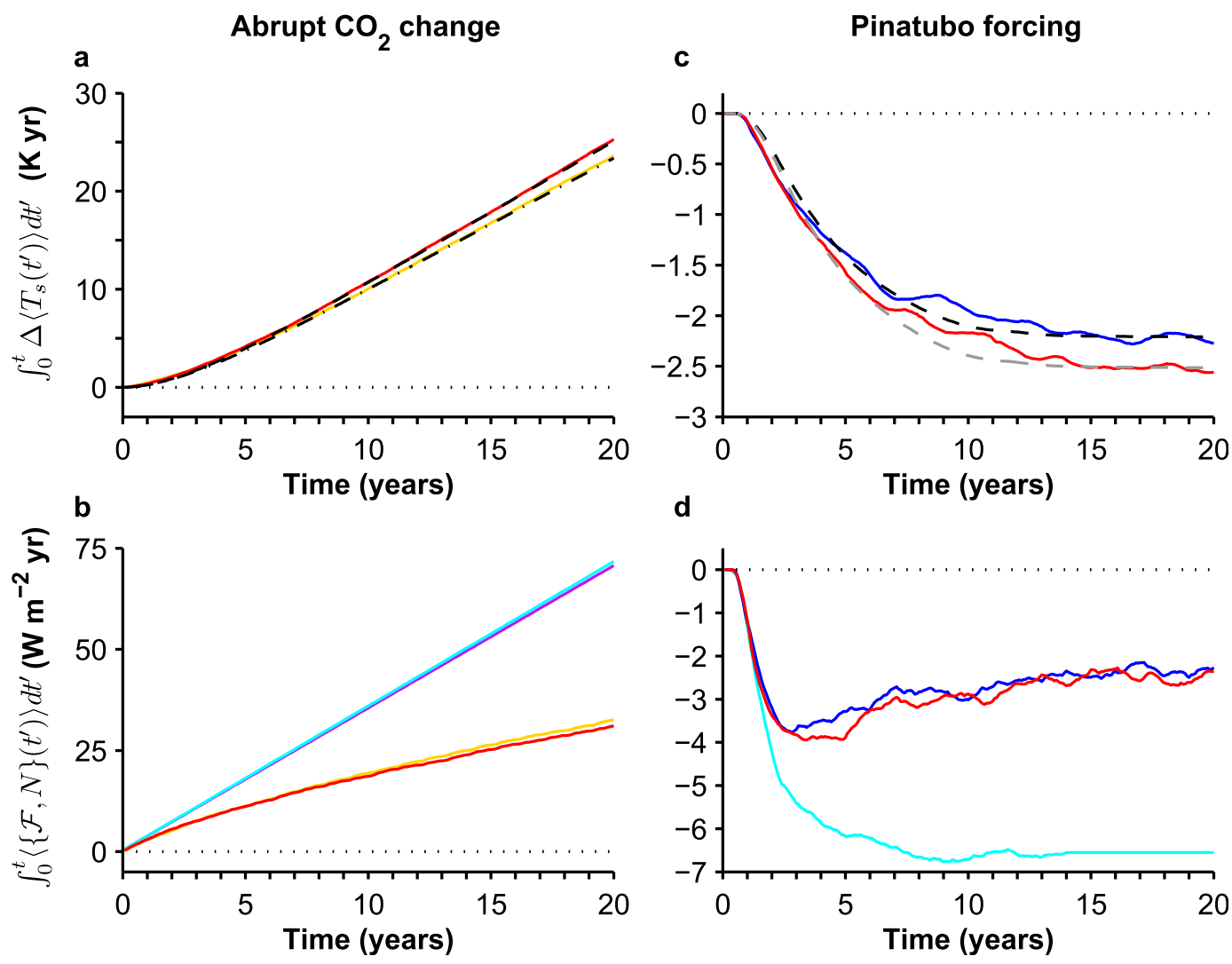

FIG. 3. (a) Time-integrated change in global-mean surface temperature for abrupt $\mathrm{CO}_{2}$ simulations $\left(2 \times \mathrm{CO}_{2}\right.$, red line, and the reflection of $0.5 \times \mathrm{CO}_{2}$ about zero, yellow line) with black dashed line showing the two-box fit model [(4)] for $2 \times \mathrm{CO}_{2}$ and black dashed-dotted line showing the two-box model fit for $0.5 \times \mathrm{CO}_{2}$ (estimated parameters in Table 1). (b) Time-integrated global-mean TOA radiative forcing (coinciding light blue and purple lines) and net radiation for $\mathrm{CO}_{2}$ simulations (with $0.5 \times \mathrm{CO}_{2}$ reflected about zero). (c) Time-integrated change in global-mean surface temperature for Pinatubo simulations (positive ENSO, blue, and negative ENSO, red) with dashed lines showing the integral fit TCS estimate plotted with the $\mathrm{CO}_{2}$ time scale (positive ENSO, black, and negative ENSO, gray). (d) Time-integrated global-mean TOA net radiation and radiative forcing (light blue) for Pinatubo simulations. All quantities shown are the ensemble mean of CM2.1 simulations.

expected from the two-box model with well-separated time scales.

\section{b. Two-box model interpretation}

The estimated parameters of the simplified two-box model [(4)] are $\tau_{F}=2.8 \mathrm{yr}$ and TCS $=1.4 \mathrm{~K}$ (Table 1$)$. The $0.5 \times \mathrm{CO}_{2}$ and $2 \times \mathrm{CO}_{2}$ have similar time scales and transient climate sensitivities, with the TCS about $5 \%$ smaller in the $0.5 \times \mathrm{CO}_{2}$ case. The fast time scale $\tau_{F} \approx$ $3 \mathrm{yr}$ is shorter, and more accurate, than the $\tau_{F} \approx 4 \mathrm{yr}$ described in Held et al. (2010). The difference arises because we use monthly time averages here, whereas Held et al. (2010) used annual time averages.

The decomposition of $\widetilde{\beta}$ into the sum of the climate feedbacks $\beta$ and the ocean heat uptake per unit warming $\gamma$ shows a larger contribution from the climate feedbacks $\beta=1.6 \mathrm{~W} \mathrm{~m}^{-2} \mathrm{~K}^{-1}$ than the ocean heat uptake $\gamma=1.0 \mathrm{~W} \mathrm{~m}^{-2} \mathrm{~K}^{-1}$ (Table 1). The decomposition of $\widetilde{\beta}$ reveals that the difference in the ocean heat uptake efficiency rather than the climate feedbacks or radiative forcing accounts for the roughly $5 \%-10 \%$ difference between temperature change in the $0.5 \times \mathrm{CO}_{2}$ and $2 \times$ $\mathrm{CO}_{2}$ simulations ${ }^{4}$ (Table 1). This asymmetry in ocean heat uptake between warming and cooling perturbations has implications for sea level, as explored in Bouttes et al. (2013).

The value of $\beta$ is similar in these abrupt doubling or halving simulations and in the $1 \% \mathrm{yr}^{-1} \mathrm{CO}_{2}$ increase

\footnotetext{
${ }^{4}$ That magnitude of the net radiation anomalies $\left(N \approx \mathcal{H} \approx \gamma T_{F}\right)$ is larger in the $0.5 \times \mathrm{CO}_{2}$ simulations than in the $2 \times \mathrm{CO}_{2}$ simulations is consistent with the larger $\gamma$ of $0.5 \times \mathrm{CO}_{2}$ having a bigger effect on the net radiation than the smaller $T: \gamma_{0.5 \times} / \gamma_{2 \times}>T_{2 \times} /$ $\left|T_{0.5 \times}\right|>1$ because $T \approx \mathcal{F}(\beta+\gamma)^{-1}$ decreases at a rate that is slower than linear in $\gamma$, whereas the ocean heat uptake increases linearly in $\gamma$.
} 
TABLE 1. Summary of estimates of two-box model parameters for the ensemble mean of CM2.1 simulations with different radiative perturbations. For the $1 \% \mathrm{yr}^{-1} \mathrm{CO}_{2}$ increase scenario, we use the published temperature change $(1.5 \mathrm{~K})$, TOA net radiation $\left(1.0 \mathrm{~W} \mathrm{~m}^{-2}\right)$, and radiative forcing $\left(3.5 \mathrm{~W} \mathrm{~m}^{-2}\right)$ at the time of $\mathrm{CO}_{2}$ doubling from Table 2 of Winton et al. (2010) and assume the surface energy storage is negligible to estimate $\widetilde{\beta}$ [i.e., $\widetilde{\beta}=\mathcal{F}_{2 \times \mathrm{CO}_{2}} / T\left(t_{2 \times \mathrm{CO}_{2}}\right)$ ]. These values are similar to those $(\beta=1.74, \gamma=0.73)$ obtained by Gregory and Forster (2008) using linear regression over the entire period of increasing radiative forcing.

\begin{tabular}{|c|c|c|c|c|c|c|}
\hline Radiative perturbation & Estimation technique & TCS (K) & $\widetilde{\beta}\left(\mathrm{W} \mathrm{m}^{-2} \mathrm{~K}^{-1}\right)$ & $\beta$ & $\gamma$ & $\tau(\mathrm{yr})$ \\
\hline $2 \times \mathrm{CO}_{2}$ & Two parameter & 1.45 & 2.4 & 1.6 & 0.85 & 2.8 \\
\hline $0.5 \times \mathrm{CO}_{2}$ & Two parameter & 1.35 & 2.7 & 1.65 & 1.05 & 2.7 \\
\hline $1 \% \mathrm{yr}^{-1} \mathrm{CO}_{2}$ increase & See caption & 1.5 (TCR) & 2.33 & 1.67 & 0.67 & - \\
\hline Pinatubo (positive ENSO) & Two parameter & 1.0 & 3.5 & 1.9 & 1.6 & 2.1 \\
\hline Pinatubo (negative ENSO) & Two parameter & 1.2 & 3.0 & 1.7 & 1.3 & 2.3 \\
\hline Pinatubo (positive ENSO) & Integral & 1.2 & 3.0 & 1.9 & 1.1 & - \\
\hline Pinatubo (negative ENSO) & Integral & 1.4 & 2.6 & 1.7 & 0.9 & - \\
\hline
\end{tabular}

simulation, though the ocean heat uptake efficiency is smaller in that scenario: 0.67 for $1 \% \mathrm{yr}^{-1} \mathrm{CO}_{2}$ increase compared to 0.9 and 1.15 for $2 \times \mathrm{CO}_{2}$ and $0.5 \times \mathrm{CO}_{2}$ (Table 1). Even though the evidence of a role for decadal time scales in this GCM's response is subtle, there is enough partial saturation of heat uptake on these time scales to modify the uptake efficiency $\gamma$ significantly. This apparent time dependence of the uptake efficiency $\gamma$ reflects that we have neglected changes in the deep ocean temperature $\left[\mathcal{H}=\gamma\left(T-T_{D}\right) \approx \gamma T\right]$, an approximation that breaks down over time. The effect of this difference in $\gamma$ on the TCR or TCS is reduced because $\gamma$ is less than $\beta$. The fit to the $2 \times \mathrm{CO}_{2}$ forcing simulations underestimates the TCR by a few percent; the fit to the $0.5 \times \mathrm{CO}_{2}$ forcing simulations underestimates TCR by roughly $10 \%$.

The integrated temperature response is linear in time after the rapid adjustment of the near-surface ocean, following the linear increase in the integrated radiative forcing. The integrated TOA net radiation is also growing approximately linearly in time during the $20-\mathrm{yr}$ integration (Fig. 3), as expected from the dominance of the fast component of the temperature response $T \approx \mathcal{F} /(\beta+\gamma)$.

\section{Mount Pinatubo radiative forcing}

\section{a. GCM response: $C M 2.1$}

The ensemble of CM2.1 Mount Pinatubo stratospheric aerosol forcing simulations shows a global-mean surface temperature cooling maximum of about $0.5 \mathrm{~K}$, occurring about 1 year after the eruption in June of year 0 (Fig. 1c). The surface temperature anomaly decays to near zero after about 10 years. The evolution of the global-mean surface temperature is similar for simulations initialized from La Niña conditions (negative ENSO phase; red line in Fig. 1c) and for simulations initialized from El Niño conditions (positive ENSO phase; blue line in Fig. 1c). The temperature anomalies in these simulations are consistent with Microwave Sounding Unit observations in both the lower troposphere and the stratosphere (Stenchikov et al. 2009), when ENSO is removed from the Microwave Sounding Unit observations through the approach of Santer et al. (2001). In multimodel analysis of CMIP3 simulations, authors have found CM2.1 to have either a larger response to Pinatubo (Fyfe et al. 2010) or a smaller response to Pinatubo (Bender et al. 2010) than the mean CMIP3 model analyzed, presumably because of differences in the authors' approaches to filtering internal variability.

The radiative forcing reaches a maximum of about $-3 \mathrm{~W} \mathrm{~m}^{-2}$ less than a year after the eruption and decays toward zero a few years after the eruption (Fig. 1d). The change in TOA net radiation is negative during the first three years of the simulations before returning to nearzero values (with similar results for the negative ENSO phase ensemble, not shown). The offset between the change in TOA net radiation and the radiative forcing is due to the radiative feedbacks $\beta T$, as is illustrated by the dashed line in Fig. 1d.

The integrated temperature response is shown in Fig. 3. It is -2.2 and $-2.5 \mathrm{~K}$ yr for the Pinatubo simulations initialized in the positive and negative phase of ENSO, respectively. ${ }^{5}$ The integrated radiative forcing is $-6.5 \mathrm{~W} \mathrm{~m}^{-2} \mathrm{yr}$, and the integrated TOA net radiation remains negative at the end of the 20-yr integration (the ocean heat content is lower than that of the control simulation), a signature of the magnitude of longtime-scale response. Stenchikov et al. (2009) discuss the ocean heat content changes in these simulations in more detail.

\footnotetext{
${ }^{5}$ We find a substantially different integrated temperature response to Pinatubo than Bender et al. (2010), who extracted the Pinatubo response from simulations in which multiple forcing agents are active: about $-1.5 \mathrm{Kyr}$ (Fig. 3) compared to their $-0.5 \mathrm{~K}$ yr over the $5 \mathrm{yr}$ following the eruption.
} 


\section{b. Two-box model interpretation}

The transient climate sensitivity obtained using the integral fit $[(7)]$ is about $1.3 \mathrm{~K}$. There is some dependence on the phase of ENSO: the estimate from the ensemble-mean of simulations initialized in the positive phase of ENSO is lower $(1.2 \mathrm{~K})$ than the estimate from the ensemble-mean of simulations initialized in the negative phase of ENSO (1.4 K). This is consistent with the differences in the integrated temperature response (Fig. 3). Although this difference falls short of $10 \%$ significance, it suggests that further study of the effect of ENSO phase on the volcanic response is warranted. As Mount Pinatubo erupted during a positive phase of ENSO, we note that the positive ENSO ensemble-mean estimate here, taken at face value, underestimates the GCM's TCR by about $20 \%$.

The values of $\beta$ and $\gamma$ obtained with the integral fit are close to those obtained in the abrupt $\mathrm{CO}_{2}$-forcing simulations, but the value of $\gamma$ is once again larger than that in the $1 \% \mathrm{yr}^{-1} \mathrm{CO}_{2}$ increase scenario. (At face value, the value of $\beta$ is primarily responsible for the difference in TCS for the positive and negative ENSO ensembles.) For the integral fit, the ratio of $\gamma$ to $\beta$ is $0.5-$ 0.6 in the Pinatubo simulations, which is close to the value of 0.6 obtained in the abrupt $\mathrm{CO}_{2}$ simulations (Table 1). The TCS and ocean heat uptake efficiency Pinatubo simulations are more similar to the abrupt $\mathrm{CO}_{2}$ simulations than the $1 \% \mathrm{yr}^{-1} \mathrm{CO}_{2}$ increase scenario, with the uptake efficiency greater in the Pinatubo simulations.

The spatial pattern of the surface temperature change is important in determining the relationship between the global-mean surface temperature and the top-ofatmosphere energy balance (Hansen et al. 2005; Winton et al. 2010). Figure 2 shows the surface temperature change normalized by the global-mean surface temperature for the ensemble-mean of $\mathrm{CO}_{2}$ simulations and Pinatubo simulations. The large-scale spatial pattern of the surface temperature change is similar between the different forcing types: the temperature change is less than the global-mean change in the Southern Ocean and North Atlantic and is greater than the global-mean change over land and in the Arctic. This suggests that the agreement in the partitioning of the transient climate sensitivity between the radiative feedbacks and ocean heat uptake is due to the similarity of the forced response and is not coincidental. Though the pattern of the large-scale surface temperature response is generally similar between the ensembles of simulations, there are interesting regional differences between the Pinatubo simulations and $\mathrm{CO}_{2}$ simulations (e.g., Southern Hemisphere land regions).
The TCS obtained using the two-parameter fit for the Pinatubo ensemble-mean is lower than that obtained using the integral fit (Table 1). The time scale is smaller than in the two-parameter $\mathrm{CO}_{2}$ fits because of the difference in $\widetilde{\beta}\left(c_{F}\right.$ is similar in the volcanic and abrupt $\mathrm{CO}_{2}$ simulations). The radiative feedbacks $\beta$, estimated using the TOA radiation balance, are similar to those obtained with the integral fit, whereas the ocean heat uptake efficiency $\gamma$, estimated as the residual $(\widetilde{\beta}-\beta)$, is substantially larger than that obtained with the integral fit.

Examining the time dependence of the temperature response lends insight into the source of the differences between the estimation procedures. Figure $3 \mathrm{c}$ shows that the two-box model's integrated response, using the fast time scale $\tau_{F}=2.8 \mathrm{yr}$ from the $\mathrm{CO}_{2}$ simulations and the integral fit for the TCS, underestimates the GCMsimulated response at short time scales $(1-3 \mathrm{yr})$ and overestimates the response about 10 years after the eruption before converging at 15 years (as required by the parameter estimation technique). Estimating the TCS using the integral fit weighs all times equally. In contrast, the presence of the faster responses $(<3 \mathrm{yr})$ in the GCM, which accounts for the initial difference, will lower the TCS estimate when the two-parameter fit is used, as mentioned in section $2 c$. To the extent that the global-mean temperature response cannot be fit with only one active time scale, the result will be sensitive to the fitting procedure. By construction, the integral fit captures the net temperature change up to the time at which the integral is truncated, so it provides the information of most relevance to estimates of TCR.

The integrated temperature response is still increasing slowly 10 years after eruption (Fig. 3c), so it affects the TCS estimate when the integral fit is used. However, after 10 years the magnitude of the temperature anomaly is small $(\sim 0.1 \mathrm{~K}$; Fig. $1 \mathrm{c})$, and we note that a temperature anomaly of this magnitude would likely be within noise of background variability in observations or in individual realizations of GCM simulations.

\section{c. GCM response: $C M 3$}

The ensemble-mean of CM3 simulations perturbed with Mount Pinatubo stratospheric aerosol forcing has a maximum cooling of about $-0.5 \mathrm{~K}$ occurring somewhat more than 1 year after the eruption begins, which is followed by a gradual return to unperturbed temperatures over the following decade (Fig. 4). The response of CM3 is similar to that of CM2.1. The maximum cooling is larger in CM3 than in CM2.1 and occurs somewhat later, but CM3's time-integrated response of $-2.0 \mathrm{~K} \mathrm{yr}$ is somewhat smaller than that of CM2.1.

The time-integrated top-of-atmosphere net radiation in CM3 is compared to CM2.1 in Fig. 4. In both GCMs, 


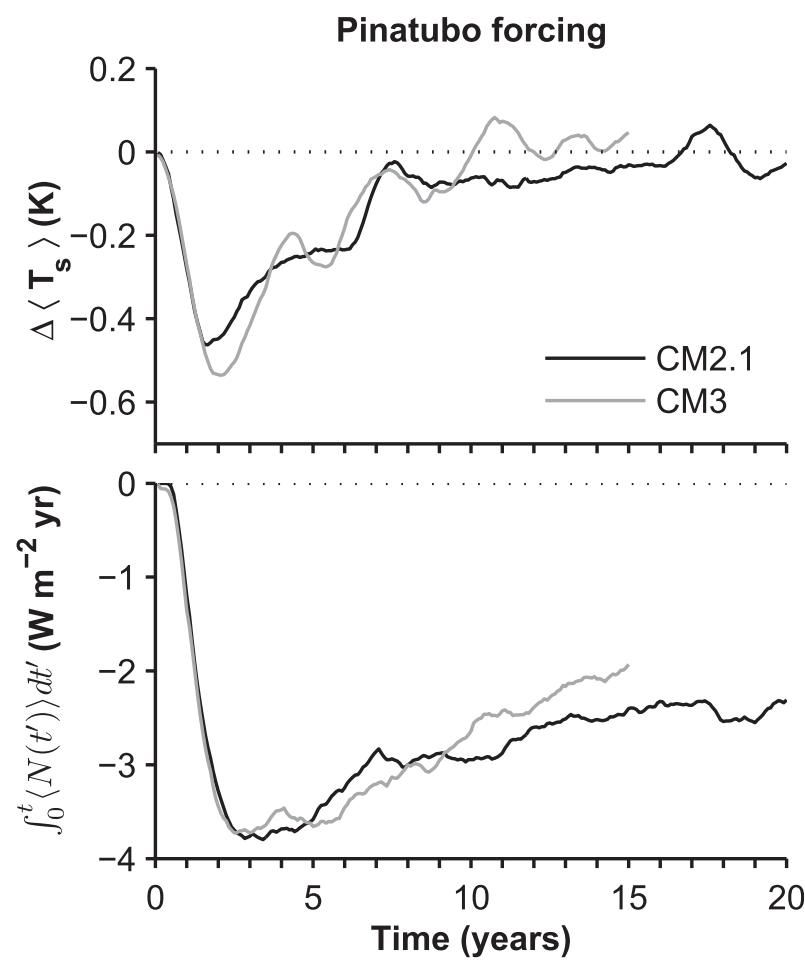

FIG. 4. (top) Change in global-mean surface temperature (12-month running time average) for CM2.1 Pinatubo simulations (black) and CM3 Pinatubo simulations (gray). (bottom) Timeintegrated global-mean TOA net radiation for CM2.1 Pinatubo simulations (black) and CM3 Pinatubo simulations (gray). All quantities shown are the ensemble mean and the CM2.1 simulations initialized in the positive and negative phase of ENSO have been averaged together.

negative anomalies (primarily associated with ocean heat loss) develop over the period with negative radiative forcing. The anomalies gradually decay, but do not reach the values of the unperturbed control over the posteruption phase of the perturbed simulations. The similarity of the radiative forcing and net radiation anomalies reveals that the similarity of the temperature response between CM3 and CM2.1 is not the result of the model with a higher sensitivity, CM3, balancing the radiative forcing with a greater change in ocean heat content. Instead, the sum of the climate feedbacks $\beta$ is similar between CM3 and CM2.1 on this time scale and the higher sensitivity of CM3 emerges on longer time scales.

The two-box global energy balance model interpretation of the GCM simulations assumes that there are two well-separated time scales. Typically, the longer time scale is substantially longer than 100 years in GCMs (Geoffroy et al. 2013). However, "intermediate" time scales (20-60 yr) are more prominent in other GCMs than in CM2.1 analyzed here (MacMynowski et al. 2011; Winton et al. 2013). The amplitude of the intermediate-time-scale component of the response is not large in most current GCMs. For example, the discrepancies between a two-box fit and the GCM-simulated temperature changes are modest $(\leqslant 0.5 \mathrm{~K}$ or $\$ 20 \%$ for $4 \times \mathrm{CO}_{2}$ step-function simulations) in CMIP5 models [Fig. 2 of Geoffroy et al. (2013)]. The presence of an intermediate time scale would affect the century-scale global-mean temperature change from $\mathrm{CO}_{2}$ (e.g., the TCR), while it would not affect the shorter-time-scale response from a volcanic eruption. Constraining the fast ( $\sim 4 \mathrm{yr})$ component of the climate response through volcanic eruptions provides a lower bound on the TCR. In CM2.1, the fits to volcanic responses provide a rather subtle underestimate of TCR, but this underestimate could be larger in other models.

The Pinatubo simulations of CM3 provide a concrete illustration of these intermediate-time-scale issues (Fig. 4). This GCM shows a similar response to Pinatubo forcing as in the CM2.1 results, so the TCS estimated from these simulations is also similar (not shown). However, CM3 has $~ 25 \%$ larger TCR than CM2.1. Winton et al. (2013) fit a three exponential time-scale response function to CM3's global-mean surface temperature response to abrupt $\mathrm{CO}_{2}$ quadrupling. They found a response of fast time scale $\sim 3 \mathrm{yr}$ with amplitude $1.5 \mathrm{~K}$, which is similar to the fast component of CM2.1. $\mathrm{CM} 3$ also has a $1.3 \mathrm{~K}$ amplitude response with a $\sim 50-\mathrm{yr}$ time scale, according to this three exponential fit. On the time scale that the TCR is evaluated, this augments the fast response by $0.4 \mathrm{~K}$ and accounts for CM3's higher TCR $(1.9 \mathrm{~K})$ than that of CM2.1 $(1.5 \mathrm{~K})$. Therefore, intermediate time scales are not constrained by a single volcanic eruption and have the potential to augment the response in century-scale scenarios, such as that which defines the TCR. To account fully for the multidecadal behavior of models with significant responses on intermediate time scales, the two-box model used here would need to be extended [cf. (1)].

\section{TCS estimates from individual CM2.1 Pinatubo realizations}

The previous sections have exclusively examined the ensemble-mean anomalies of many realizations of radiatively forced perturbation simulations with respect to corresponding control simulations. To quantify the role of internal climate variability on TCS estimates, we analyze individual realizations of Pinatubo in CM2.1 without using the corresponding control simulation. Examining individual GCM realizations of Pinatubo and withholding the control simulation is a step toward what is possible with observations of Pinatubo, though we continue make use of the GCM's radiative forcing. 
The global-mean surface temperature of the individual Pinatubo realizations is decomposed into four components: the volcanically forced anomaly, the seasonally varying climatology, anomalies associated with ENSO, and the long-term anomaly from the climatology present at the start of the volcanic radiative forcing perturbation. The global-mean volcanically forced anomaly is separated from the other components as follows:

$\Delta\langle T\rangle_{\mathrm{VOLC}}=\langle T\rangle-\langle T\rangle_{\mathrm{CLIM}}-\Delta\langle T\rangle_{\mathrm{ENSO}}-\Delta\langle\bar{T}\rangle$,

where $\langle T\rangle$ is the global-mean surface temperature time series of the volcanically perturbed simulation; $\langle T\rangle_{\text {CLIM }}$ is the GCM's climatological monthly mean, global-mean surface temperature; $\Delta\langle T\rangle_{\text {ENSO }}$ is the component of the global-mean surface temperature anomaly related to the phase of ENSO; and $\Delta\langle\bar{T}\rangle$ is the 10 -yr anomaly preceding the volcanic perturbation, which accounts for the drift present in the control simulation at the start of the volcanic perturbation simulation (but does not account for long-term linear trends in the control simulation). The ENSO temperature anomaly uses a 3-month lag regression between the Niño-3.4 region surface temperature anomaly and the global-mean surface temperature with a regression coefficient of 0.11 ; the lag and regression coefficient are the least squares estimate from the control simulation and are similar to observational estimates (e.g., Foster and Rahmstorf 2011). The volcanically forced temperature anomaly $\Delta\langle T\rangle_{\text {VOLC }}$ defined in this manner does not make use of the corresponding segment of the unperturbed simulation.

There are some differences between positive and negative phase of ENSO in the estimated TCS for both the ensemble-mean and the median of the individual realizations. However, the difference in the mean TCS estimate is not statistically significant at the $10 \%$ level. In addition, the difference between the phases of ENSO is not statistically significant if temperature anomalies are defined with respect to unperturbed control simulations. So, we combine the two phases of ENSO in the results presented in this section.

Figure 5 shows a box-and-whiskers plot of the estimated TCS for the 20 total ensemble members, using the two-parameter fitting technique. The interquartile range of TCS estimates from individual Pinatubo realizations is about $\pm 30 \%$ of the median ensemble member estimate. The median TCS estimate from the individual realizations is between the ensemble-mean estimates for the two phases of ENSO. Both the median TCS estimate from the individual realizations and the ensemble-mean estimates are biased low relative to the TCS of the ensemble mean of $0.5 \times \mathrm{CO}_{2}$ simulations (Fig. 5). As previously mentioned in section $2 \mathrm{c}$, this fitting technique

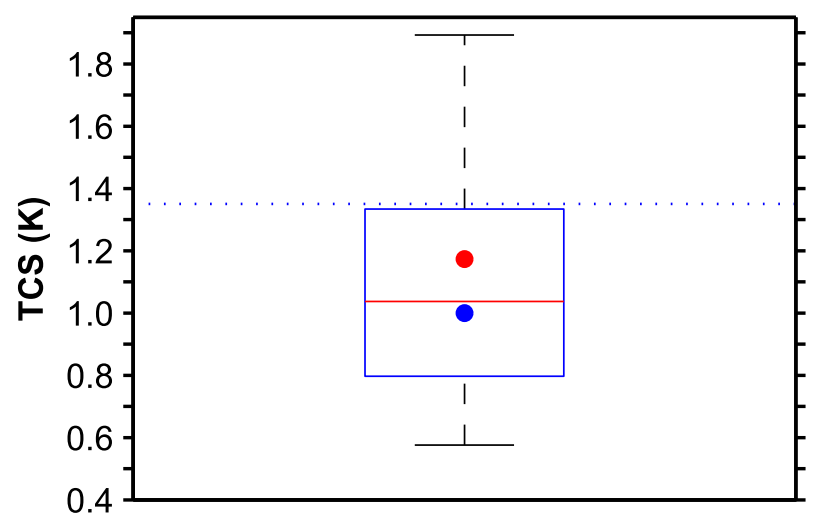

FIG. 5. Box-and-whiskers plot of the estimated TCS for 20 individual realizations of Pinatubo in CM2.1 (combining realizations initialized in the positive and negative phase of ENSO) with red line indicating the median estimate, horizontal blue lines indicating the first and third quartile estimate, black whiskers indicating the most extreme estimate, and filled circles showing the estimate from the ensemble mean (positive ENSO in blue and negative ENSO in red, Table 1). The blue dotted line is the ensemble-mean TCS from the $0.5 \times \mathrm{CO}_{2}$ simulations. The TCS is estimated using the twoparameter $\left(\widetilde{\beta}, c_{F}\right)$ fitting technique. The ensemble-mean estimates use anomalies defined with respect to the corresponding control simulations, while the individual realizations do not.

is biased low when the response is composed of multiple short time scales.

While the ensemble-mean Pinatubo temperature response remains negative throughout the 20-yr integration (Fig. 1), individual Pinatubo realizations may have positive temperature anomalies. Positive temperature anomalies occur approximately 10 years after the eruption in some realizations and are associated with either long-term positive drift in the control simulation (we have not removed the control simulation's long-term linear trend) or ENSO global-mean temperature anomalies which are not linearly related to the Niño-3.4 region anomalies. The presence of these positive temperature anomalies in some realizations makes the integral fit sensitive to the time of truncation, $\tau_{I}$ in (5). The spread in integral fits for individual Pinatubo realizations is comparable to the two-parameter fit, provided one accounts for this sensitivity (e.g., by truncating the integral when the volcanic temperature anomaly becomes positivethe opposite sign of the radiative forcing).

\section{Discussion: Implications for the observed climate record}

We briefly mention some issues regarding the interpretation of the historical temperature record and attempts to decompose it into forced (natural and anthropogenic) and internal variability (e.g., ENSO) components. First, analyses of the historical record of 
global-mean surface temperature that remove a lagged regression between stratospheric aerosol optical depth and surface temperature (e.g., Lean and Rind 2008; Foster and Rahmstorf 2011) are not consistent with GCM simulations. One is better off using the single-time-scale energy balance model [(4)]. The time-dependent temperature response to volcanic eruptions does not have the same shape as the radiative forcing (Fig. 1b), but this difference in shape is captured reasonably well with this simple energy balance model.

Second, some published techniques to separate ENSO and volcanic contributions to global-mean surface temperature impose a transient climate sensitivity (Santer et al. 2001; Thompson et al. 2009). The GCM results presented here suggest that an appealing approach for future observational analyses is to assume the long-term trend of the filtered time series and the extracted volcanic signal are governed by the same transient climate sensitivity.

Finally, the possible presence of an intermediate time scale affects the interpretation of the climate record. Multiple volcanic eruptions occurred near the beginning of the twentieth century and between 1960 and 1991 . Clustering of multiple eruptions on the time scale of a few decades will enhance the component of the volcanic forcing that projects onto the intermediate-timescale climate response. Without more clarity concerning the relevant dynamics and the lack of robustness across GCMs, the multidecadal component of the response is a potential source of uncertainty in attribution studies.

\section{Conclusions}

Observed climate changes may place constraints on the transient climate sensitivity. The response of the climate to volcanic eruptions, such as the eruption of Mount Pinatubo, is potentially useful to this end. While a short-time-scale event is unlikely in isolation to tightly constrain the equilibrium climate sensitivity, which depends in part on the long-time-scale responses, it may constrain the fast-time-scale climate response to radiative forcing. A central goal of this work is to examine the extent to which this is true of volcanic eruptions in wellcontrolled GCM simulations with known radiative forcing.

For volcanic radiative forcing, the estimated transient climate sensitivity (TCS) is sensitive to the estimation procedure (i.e., there is nonnegligible norm dependence to the fits). The GCM responses, over the first few years when the response is largest, are not perfectly fit with a one time-scale model. If the goal is to relate these responses to forcing with longer time scales, using an integral over time to estimate the TCS appears to be more appropriate than fitting the time-dependent evolution in more detail. However, this assumes that there is no other information available. If there is some independent information on the effective heat capacity, in particular, one can hope to constrain sensitivity from the time evolution with little or no sensitivity to the forcing magnitude. But one will still be constrained by the adequacy of the one fast-time-scale model.

We find the TCS estimated with this integral fit technique from simulations of the response to the eruption of Mount Pinatubo is very similar to that of the initial fast response to abruptly changed $\mathrm{CO}_{2}$ concentration in GFDL CM2.1. The decomposition of the TCS into components associated with the TOA radiative feedbacks and ocean heat uptake is likewise similar between the different radiative forcing types, which is consistent with the similarity of the spatial pattern of the forced response (Fig. 2). However, the ocean heat uptake per unit warming is larger in both the abrupt $\mathrm{CO}_{2}$ simulations and Pinatubo simulations than in the $1 \% \mathrm{yr}^{-1} \mathrm{CO}_{2}$ increase simulation (Table 1), which may be related to the time evolution in the ocean heat uptake efficiency or the spatial pattern of the temperature change. There is also $\sim 5 \%$ difference in TCS between warming and cooling, as determined from the $\mathrm{CO}_{2}$ forced simulations, with larger TCS for warming. This asymmetry is associated with differences in ocean heat uptake efficiency $\gamma$, so it is reasonable to expect, on this basis alone, a difference of this magnitude $(\sim 5 \%)$ in the TCS estimated from the cooling perturbation of a volcanic eruption compared to the warming perturbation from increased greenhouse gas concentrations. Differences in heat uptake efficiency that emerge in the $1 \% \mathrm{yr}^{-1} \mathrm{CO}_{2}$ increase scenario then enhance this difference, with the underestimate of the TCR from the volcanic response closer to $10 \%-15 \%$ for CM2.1.

However, comparison to a model with larger transient climate response, GFDL CM3, and with more of the warming to an abrupt increase in $\mathrm{CO}_{2}$ occurring on multidecadal time scales, confirms that the underestimate of TCR from the volcanic response can be substantially larger than in CM2.1.

Individual realizations of volcanic eruptions in CM2.1 produce a range of estimates for the transient climate sensitivity $(0.8-1.3 \mathrm{~K}$ interquartile range of both phases of ENSO for the two-parameter fit). There are likely to be better ways of removing ENSO and other components of internal variability, using multivariate techniques, so as to reduce the spread in TCS estimates.

The upper bound of the interquartile range for individual realizations of the volcanic responses in CM2.1 is slightly less than the GCM's TCR of $1.5 \mathrm{~K}$. The range of TCR in the CMIP3 ensemble is 1.2-2.6 K (Randall 
et al. 2007) and is 1.1-2.6 K in CMIP5 (Flato et al. 2013). On this basis it appears that one can infer with some confidence from single realizations of CM2.1's volcanic response that its TCR lies in the lower half of this model ensemble, so there is the potential to use the observed response to Pinatubo to narrow the range of TCR. However, even this limited result depends on there being only a small component of the response on interdecadal time scales, as the results from the CM3 simulations illustrate.

An observational estimate of TCS from the eruption of Mount Pinatubo will require consideration of the factors outlined here (sensitivity to parameter estimation technique, asymmetry between warming and cooling, and a possible dependence on the phase of ENSO), as well as those omitted in our analysis of GCM simulations (uncertainty in knowledge of the radiative forcing). Observationally constraining the fast component of the climate response should be interpreted as a lower bound on the century-scale warming or TCR because lower-frequency, multidecadal climate responses can potentially augment the fast response.

Acknowledgments. TMM was supported by a Princeton Center for Theoretical Science fellowship. We thank Yi Ming for useful discussions and Mike Winton, Ron Stouffer, Kyle Armour, and Olivier Geoffroy for helpful reviews of the manuscript.

\section{REFERENCES}

Anderson, J. L., and Coauthors, 2004: The new GFDL global atmosphere and land model AM2-LM2: Evaluation with prescribed SST simulations. J. Climate, 17, 4641-4673, doi:10.1175/JCLI-3223.1.

Armour, K. C., C. M. Bitz, and G. H. Roe, 2013: Time-varying climate sensitivity from regional feedbacks. J. Climate, 26, 4518-4534, doi:10.1175/JCLI-D-12-00544.1.

Bender, F. A. M., A. M. L. Ekman, and H. Rodhe, 2010: Response to the eruption of Mount Pinatubo in relation to climate sensitivity in the CMIP3 models. Climate Dyn., 35, 875-886, doi:10.1007/s00382-010-0777-3.

Boer, G. J., M. Stowasser, and K. Hamilton, 2007: Inferring climate sensitivity from volcanic events. Climate Dyn., 28, 481-502, doi:10.1007/s00382-006-0193-x.

Bouttes, N., J. M. Gregory, and J. A. Lowe, 2013: The reversibility of sea level rise. J. Climate, 26, 2502-2513, doi:10.1175/ JCLI-D-12-00285.1.

Church, J. A., N. J. White, and J. M. Arblaster, 2005: Significant decadal-scale impact of volcanic eruptions on sea level and ocean heat content. Nature, 438, 74-77, doi:10.1038/ nature 04237 .

Delworth, T. L., and Coauthors, 2006: GFDL's CM2 global coupled climate models. Part I: Formulation and simulation characteristics. J. Climate, 19, 643-674, doi:10.1175/ JCLI3629.1.
Donner, L. J., and Coauthors, 2011: The dynamical core, physical parameterizations, and basic simulation characteristics of the atmospheric component AM3 of the GFDL global coupled model CM3. J. Climate, 24, 3484-3519, doi:10.1175/ 2011JCLI3955.1.

Flato, G., and Coauthors, 2013: Evaluation of climate models. Climate Change 2013: The Physical Science Basis, T. F. Stocker et al., Eds., Cambridge University Press, 741-866.

Foster, G., and S. Rahmstorf, 2011: Global temperature evolution 1979-2010. Environ. Res. Lett., 6, 044022, doi:10.1088/ 1748-9326/6/4/044022.

Fyfe, J. C., N. P. Gillett, and D. W. J. Thompson, 2010: Comparing variability and trends in observed and modelled global-mean surface temperature. Geophys. Res. Lett., 37, L16802, doi:10.1029/2010GL044255.

Geoffroy, O., D. Saint-Martin, D. J. L. Olivié, A. Voldoire, G. Bellon, and S. Tytéca, 2013: Transient climate response in a two-layer energy-balance model. Part I: Analytical solution and parameter calibration using CMIP5 AOGCM experiments. J. Climate, 26, 1841-1857, doi:10.1175/ JCLI-D-12-00195.1.

Good, P., J. M. Gregory, and J. A. Lowe, 2011: A step-response simple climate model to reconstruct and interpret AOGCM projections. Geophys. Res. Lett., 38, L01703, doi:10.1029/ 2010 GL045208.

Gregory, J. M., 2000: Vertical heat transports in the ocean and their effect on time-dependent climate change. Climate Dyn., 16, 501-515, doi:10.1007/s003820000059.

_ , and P. M. Forster, 2008: Transient climate response estimated from radiative forcing and observed temperature change. J. Geophys. Res., 113, D23105, doi:10.1029/2008JD010405.

Griffies, S. M., and Coauthors, 2011: The GFDL CM3 coupled climate model: Characteristics of the ocean and sea ice simulations. J. Climate, 24, 3520-3544, doi:10.1175/ 2011JCLI3964.1.

Hansen, J., and Coauthors, 2005: Efficacy of climate forcings. J. Geophys. Res., 110, D18104, doi:10.1029/2005JD005776.

Held, I. M., M. Winton, K. Takahashi, T. Delworth, F. Zeng, and G. K. Vallis, 2010: Probing the fast and slow components of global warming by returning abruptly to preindustrial forcing. J. Climate, 23, 2418-2427, doi:10.1175/2009JCLI3466.1.

Kostov, Y. K., K. C. Armour, and J. Marshall, 2014: Impact of the Atlantic meridional overturning circulation on ocean heat storage and transient climate change. Geophys. Res. Lett., 41, 2108-2116, doi:10.1002/2013GL058998.

Lean, J. L., and D. H. Rind, 2008: How natural and anthropogenic influences alter global and regional surface temperatures: 1889 to 2006. Geophys. Res. Lett., 35, L18701, doi:10.1029/ 2008 GL034864.

Liang, M.-C., L.-C. Lin, K.-K. Tung, Y. L. Yung, and S. Sun, 2013: Transient climate response in coupled atmospheric-ocean general circulation models. J. Atmos. Sci., 70, 1291-1296, doi:10.1175/JAS-D-12-0338.1.

Lindzen, R. S., 1994: Climate dynamics and global change. Annu. Rev. Fluid Mech., 26, 353-378, doi:10.1146/ annurev.fl.26.010194.002033.

_ canic cooling. J. Geophys. Res., 103, 5929-5941, doi:10.1029/ 98JD00125.

MacMynowski, D. G., H. J. Shin, and K. Caldeira, 2011: The frequency response of temperature and precipitation in a climate model. Geophys. Res. Lett., 38, L16711, doi:10.1029/ 2011 GL048623. 
Olivié, D. J. L., G. P. Peters, and D. Saint-Martin, 2012: Atmosphere response time scales estimated from AOGCM experiments. J. Climate, 25, 7956-7972, doi:10.1175/ JCLI-D-11-00475.1.

Padilla, L. E., G. K. Vallis, and C. W. Rowley, 2011: Probabilistic estimates of transient climate sensitivity subject to uncertainty in forcing and natural variability. J. Climate, 24, 5521-5537, doi:10.1175/2011JCLI3989.1.

Randall, D. A., and Coauthors, 2007: Climate models and their evaluation. Climate Change 2007: The Physical Science Basis, S. Solomon, et al., Eds., Cambridge University Press, 590-662.

Raper, S. C. B., J. M. Gregory, and R. J. Stouffer, 2002: The role of climate sensitivity and ocean heat uptake on AOGCM transient temperature response. J. Climate, 15, 124-130, doi:10.1175/1520-0442(2002)015<0124:TROCSA > 2.0.CO;2.

Santer, B. D., and Coauthors, 2001: Accounting for the effects of volcanoes and ENSO in comparisons of modeled and observed temperature trends. J. Geophys. Res., 106, $28033-$ 28 059, doi:10.1029/2000JD000189.

Siegenthaler, U., and H. Oeschger, 1984: Transient temperature changes due to increasing $\mathrm{CO}_{2}$ using simple models. Ann. Glaciol., 5, 153-159.

Soden, B. J., R. T. Wetherald, G. L. Stenchikov, and A. Robock, 2002: Global cooling after the eruption of Mount Pinatubo: A test of climate feedback by water vapor. Science, 296, 727-730, doi:10.1126/science.296.5568.727.

Stenchikov, G., T. L. Delworth, V. Ramaswamy, R. J. Stouffer, A. Wittenberg, and F. Zeng, 2009: Volcanic signals in oceans. J. Geophys. Res., 114, D16104, doi:10.1029/2008JD011673.

Stouffer, R. J., 2004: Time scales of climate response. J. Climate, 17, 209-217, doi:10.1175/1520-0442(2004)017<0209: $\mathrm{TSOCR}>2.0 . \mathrm{CO} ; 2$
- and Coauthors, 2006: GFDL's CM2 global coupled climate models. Part IV: Idealized climate response. J. Climate, 19, 723-740, doi:10.1175/JCLI3632.1.

Thompson, D. W. J., J. M. Wallace, P. D. Jones, and J. J. Kennedy, 2009: Identifying signatures of natural climate variability in time series of global-mean surface temperature: Methodology and insights. J. Climate, 22, 6120-6141, doi:10.1175/ 2009JCLI3089.1.

van Hateren, J. H., 2013: A fractal climate response function can simulate global average temperature trends of the modern era and the past millennium. Climate Dyn., 40, 2651-2670, doi:10.1007/s00382-012-1375-3.

Wigley, T. M. L., C. M. Ammann, B. D. Santer, and S. C. B. Raper, 2005: Effect of climate sensitivity on the response to volcanic forcing. J. Geophys. Res., 110, D09107, doi:10.1029/ 2004JD005557.

Winton, M., K. Takahashi, and I. M. Held, 2010: Importance of ocean heat uptake efficacy to transient climate change. J. Climate, 23, 2333-2344, doi:10.1175/2009JCLI3139.1.

—, A. Adcroft, S. M. Griffies, R. W. Hallberg, L. W. Horowitz, and R. J. Stouffer, 2013: Influence of ocean and atmosphere components on simulated climate sensitivities. J. Climate, 26, 231-245, doi:10.1175/JCLI-D-12-00121.1.

Yokohata, T., S. Emori, T. Nozawa, Y. Tsushima, T. Ogura, and M. Kimoto, 2005: Climate response to volcanic forcing: Validation of climate sensitivity of a coupled atmosphere-ocean general circulation model. Geophys. Res. Lett., 32, L21710, doi:10.1029/2005GL023542.

Yoshimori, M., and A. J. Broccoli, 2008: Equilibrium response of an atmosphere-mixed layer ocean model to different radiative forcing agents: Global and zonal mean response. J. Climate, 21, 4399-4423, doi:10.1175/2008JCLI2172.1. 